\title{
The Strategic DeVelopment of Physiotherapy IN SOUTH AFriCA PAPER 1: SOME THEORETICAL CONCEPTS Which Relate to Organisational Change
}

\begin{abstract}
This is the first of two papers which examine the relationship between professional organisations and organisational change. Different theoretical paradigms for change are outlined against the historical development of the physiotherapy profession in South Africa. An evolutionary approach using an open systems framework emphasises the need for constant interaction by the physiotherapy profession with the external environment. Some of the responses by the physiotherapy profession to the changing events and shifts in the external environment are discussed and some strategic recommendations for the continuing sustainability of the profession are made.
\end{abstract}

\section{KEYWORDS: PROFESSIONAL ORGANISATIONS; PHYSIOTHERAPY; TRANSFORMATION; THEORIES OF ORGANISATIONAL CHANGE.}

\section{INTRODUCTION}

Organisations form one of the most fundamental characteristics of modern society. They are founded as a consequence of historical necessity and resource availabilty (Aldrich 1999). Through organisations people pursue activities too broad in scope to be accomplished by individuals. Major tasks, such as health care, are addressed not by a single organisation, but by sets of interdependent organisations which include nursing, physiotherapy, medicine etc.

This is the first of two papers which seek insights into the ways the physiotherapy profession in South Africa evolved, managed and sustained itself as a small professional organisation throughout the last 30 years.

This first paper introduces modern sociological theories which underpin our understanding of professional organisations, organisational change and transformation processes. The evolution of the physiotherapy profession in South Africa will be used as an example.

\section{CORRESPONDENCE:}

Associate Professor Pat Bowerbank Physiotherapy Department Faculty of Health Sciences University of Cape Town Observatory
The second paper will relate how the profession changed over time and the course of the profession in contemporary society will be charted over the period 1970 - 1999. Chronologically, the decisions and actions that shaped the profession's history will be tracked, as well as the related trends and events which took place in the environment and impacted on the profession.

The second paper also investigates the strategies employed by physiotherapists in South Africa for professional growth and survival; and, drawing on the theoretical concepts discussed in the first paper will propose a physiotherapy paradigm for managing the health care environment in South Africa.

No formal theory has been developed which contains a physiotherapy paradigm for understanding and managing the health care environment. A number of recent authors (Paartero, 1982; Tynne-Lenne, 1991; Richardson, 1993; Grant, 1995) have challenged physiotherapy organisations world-wide to question their profession and its place and role in health care. They have suggested that the use of a paradigm as a theoretical concept could frame the questions which would help to establish an organisational identity and definition for the profession. Paradigm proliferation in organisational studies has given us a wealth of perspectives in which to view organisations and organisational change.

\section{THEORIES OF ORGANISATIONS \& ORGANISATIONAL CHANGE}

The physiotherapy organisation is not self sufficient, depending on interchanges with its environment in order to be sustained. Under the influence of modern social scientists we now recognise that organisations, such as physiotherapy, are strongly embedded in environments and environmental influences penetrate organisations in many ways.

There is an abundance of theoretical inquiry and research on the relationship between organisations and their societal contexts; organisation-environment relations; and conceptual models of organisation-environment relations (DiMaggio and Powell, 1983; Allmendinger and Hackman, 1996; Hannan and Freeman, 1977, 1989)

This paper adopts an evolutionary approach which assumes that organisations do not follow a fixed path of development, instead, external events interact with an organisation's own actions to drive the pace, pattern, and direction of change (Aldrich, 1999) organisations reform, transform and renew themselves to fit the environment. All transformations are time-dependent historical processes, generalisations 
made about the physiotherapy organisation must therefore be historically grounded and limited to the domain of the profession.

As the environments of organisations change and as the needs or demands of clientele change, organisations must, if they are to persist, be able to change. Organisations are always changing and generally change typically takes the form of episodes, distinct periods in which some shift takes place - such shifts may be in the external environment such as technology, government policy or laws, consumer demands or by changes in the internal context - structure, norms, and values.

A physiotherapy paradigm requires that the profession think of itself in terms of what it does, how it does it and how it identifies itself in terms of professional values.

The notion of a paradigm has the potential to help clarify, express and evaluate fundamental beliefs which underpin physiotherapy organisation (Richardson, 1993). This process of critical self reflection and self identification helps to determine what is given attention, what interpretations are made and what behaviours are elicited.

Kuhn (1970) used the term paradigm to express unique thinking, acting and methods of solving problems of a particular group of people.

\section{PHYSIOTHERAPY AS A PROFESSIONAL ORGANISATION}

All professions came into being to fulfil a specific social function and they are found in the division of labour which prevails with the times. Within health care, professions delineated their own sphere of activities into specialist areas as they sought to define their fields into specific occupations and to emphasise their own status. In 1970 a greater proportion of physiotherapists were employed by the state in bureaucratic institutions, either hospitals or clinics, which were perceived at that time to be the main employing bodies. The classic perspective on bureaucracy was proposed by Weber (1947) and had, as one of its main characteristics, a hierarchical structure and employment based on length of service and merit. This posed many problems to the aspirations and development of physiotherapists and to the profession itself and lead to a move, by many physiotherapists, towards the more independent private sector. Goode (1969:275) states " ... many aspiring occupations and semi professionals will never become professionals in the usual sense; they will never reach the levels of knowledge and dedication to service that society considers necessary for a profession." He goes on to say that even if they do reach professional level they will always be less professional (than eg medical doctors) in such traits as cohesion, commitments to norms of service and control over professional violations. Organisations that seek recognition must change themselves and be able to engage in transactions which include power, prestige and income.

Professional status for physiotherapists in South Africa has been an on going ambition for some time and since 1972 there has been considerable recognition of a structured body of knowledge, a regulating body with a code of practice, and recognition of autonomy of practice. Physiotherapists working in the private sector have been able to negotiate with appropriate bodies over fee structures and to establish their own incomes.

Mintzberg (1979:175) defines a professional as "someone in whom the capacity to carry out some complex, specialised work has been internalised through extensive training." and describes the function and structure of professional organisations as follows:

1. relying for co-ordination of function on the standardisation of skills and its associated training and indoctrination;

2. having considerable control over their own work but work closely with the clients served, the social system within the profession is collegial;

3. standards are maintained by the self governing professional associations which sets their own occupational and ethical guidelines;

4. professional associations set universal standards which emphasis the power of expertise and licensing system;

5. the structure of the professional organisation becomes at the same time both functional and market-based;
6. and (also) the activity is connected to some value the community considers important.

In a sense professionalism can be seen as an ideology with certain crucial characteristics associated with it (Paatero, 1981), and the position and location of physiotherapy is along a continuum of professionalisation - shifting as conditions change.

An organisation is "a social structure deliberately created and maintained to get work done" (Etzioni, 1964:195), "goal directed, boundary-maintaining and socially constructed" (Aldrich, 1999:2). Physiotherapists, as part of such a social structure, occupy three main employment roles in South Africa, the role of state employee which involves making physiotherapy skills available to the public sector; the role of educator involving the training and education of under graduate and, more recently, post graduate students; and thirdly the role of private practitioner which includes contracting an individual's skills directly to individual patients or specific organisations. The most immediate difference in the nature of the three roles is the degree to which the holder may define the role.

\section{THE PROFESSIONAL ASSOCIATION}

The professional association has to balance the diverse needs expressed by the different coalition groups amongst its membership in order to maintain a legitimate presence both internally and to the outside community of stakeholders.

Michaels (1976) describes an association as "a collection of people who agree to come together and govern themselves by certain rules in order to accomplish things which as isolated individuals they could not accomplish." The South African Society of Physiotherapy (SASP) in the form of a voluntary association came into being in 1925 , it has gone through several stages of internal restructuring and currently has approximately 3000 members.

The function of professional associations is to exert an influence on state regulators; promote collective good of the members through information sharing; obtain economic advantage; reduce legislative or competitive uncertainty through the efforts to standardise the 
services of members; and to enhance the image of the profession and its members Oliver (1990). Professional associations must be orientated towards the needs of their members by pursuing objectives which enhance the well-being, status, recognition and quality of the profession (Benveniste, 1987); through these broad objectives the association represents, controls and sets policy for the entire profession, ensuring the knowledge base is relevant to its task and thus legitimising the profession.

Thus the professional association plays a central role in defining and defending its boundaries and maintaining its relationship with the external environment, influencing and informing stakeholders and preventing encroachment from other professionals. However, the current shift in health care policy firstly away from disease orientated medicine towards a more participative client based system whereby clients take more responsibility for their own health; and secondly, encompassing a more comprehensive, multidisciplinary approach means the profession's boundaries are likely to become more blurry with a greater overlapping and sharing of common skills. This presents new challenges to the profession which has spent considerable time and effort over the past 20 years protecting its skills and scope of practice. New generic skills, broader definition of the scope of practice and a more pragmatic understanding of the task domain whilst retaining the skills which define physiotherapy are all issues facing modern physiotherapists.

The scope of practice for physiotherapy, which is prescribed and changes from time to time in line with acquired technologies and patient needs, lays down specific goals and unambiguous criteria for understanding the activity of physiotherapy; as such it legalises and legitimises the activity. However the scope of practice is likely to become more ambiguous in the future as more disciplines allied to physiotherapy such as masseurs, biokineticians and exercise therapists join the multi-disciplinary ranks. This could pose as either a threat or an opportunity to the physiotherapy profession depending on the strategic approach that is utilised.

\section{CONCEPTS OF ENVIRONMENT \& THEORIES OF ORGANISATIONAL CHANGE}

This paper adopts an open system perspective and as such views organisations as a comprehensive structure of coalition of interests and networks of interdependent activities. These are dependent on resources, information and technology from the outside environment which shapes the structure and supports the organisation. Organisations in an opensystem framework interact with their external environment which, in this context, may be defined as being composed of those institutions or forces that affect the performance of the organisation but over which the organisation has little or no direct control. Generally speaking these forces may be seen as follows: political events and changes in regimes; legal and regulatory policy change; shifts in societal norms and values; changes in resource availability.

In order to develop, organisations have to be capable of detecting trends, events, competitors, markets and technological developments in the external environment which are relevant to their survival and to which they have to adapt. Thus the physiotherapy profession has had to respond to events in the environment, developing a unique decision making process which is set in a historical context. Cycles of transformation have resulted changing the course of the profession. Transformation in this context refers to a major change in the (physiotherapy) organisation involving a break with existing routines and a shift to new kinds of competencies that challenge professional knowledge resulting in changes to goals, boundaries, and activities (Aldrich, 1999).

\section{CHANGE AND OPPORTUNITY}

Barbara Richardson (1999) writes " the aim now is to empower patients to manage their own health needs and it is proposed that this will be best supported through multi-disciplinary and interdisciplinary teamwork ... for physiotherapists, collaboration in a sociallybased, client centred model of health care is a radical change from the treatment of patients in large acute hospitals dominated by a medical model of health care"
Population ecology theory (Hannan and Freeman, 1989) explores how populations (eg physiotherapy profession) are transformed by environmental changes. Change for a particular population occurs through an evolutionary process, those better suited or which fit best to their environment survive and those that do not fit - die. New organisations are then created or evolve that embody the new needs of the environment.

Health care organisations are closely linked to external forces of both political and social nature and as such are largely dependent on those institutions to confer legitimacy and resources - both essential for their survival and fitness with the environment.

Much of the change affecting the current health care reforms in South Africa, and, for that matter in other parts of the world, is being driven by both economic reality and the need to express ideological commitment. One distinguishing feature of the private sector reforms is their focus which basically aims through a market mechanism to alter the core purpose of purchasers; whereas ideological underpinning can be seen in the public sector by a move away from essentially line managed, "high tech" curative medicine towards more comprehensive community based health care.

The complexity of the external environment and the demands and constraints which this places on the physiotherapy profession requires much effort and visionary thinking from the profession in order to sustain the growth it has experience in recent years. At the same time it offers an opportunity to move forward on many fronts challenging the decision making ability of physiotherapists to make responsible choices. Their ability to do this will depend, in part, firstly on their professional adaptability and confidence and secondly on their desire for the sustainability of the profession.

\section{CONCLUSION}

The physiotherapy profession in South Africa has evolved from a small beginning in 1925 to an established contemporary health care organisation in 2000 . This paper has drawn on a variety of sociological theories and perspectives to 
explain the pattern of change which has taken place in the professional organisation over the past $\mathbf{3 0}$ years. Reference is made to evolutionary theory which emphasises the need for legitimacy in the development of technology, normative and legal standards necessary for professional sustainability within the external environment.

Whilst reviewing material for this paper it appeared to the author that the physiotherapy profession in South Africa worked hard over the past 30 years to achieve true professional status, in so doing it concentrated on the first four professional characteristics as suggested by Mintzberg, 1979 (above). Now it has an opportunity to consolidate these characteristics into professional skills and must look to developing the fifth and sixth characteristics - thus making the profession both functional and market based whilst connecting the activity to something of value to the community.

\section{REFERENCES}

Aldrich, H.E. 1999. Organisations Evolving, Sage Publications, London

Allmendinger, J., \& Hackman, J.H. 1996. Organisations in Changing Environments. Administrative Science Quarterly 4 I, 337-369.

Benveniste, G. 1987. Professionalising the Organisation, Jossey-Bass, San Francisco

DiMaggio, P.J.,\& Powell, W.W. 1983. The Iron Cage Revisited.American Sociological Review (48), 146-160

Etzioni, A. 1964. Modern Organisations, Prentice Hall, Englewood-Cliffs

Goode, W.J. 1969. The Theoretical Limits of Professionalisation. In: The Semi Professionals and Their Organisation, ed Etzioni,A First Press, USA, 266-309.

Grant, R. 1995. The pursuit of Excellence in the Face of Constant Change. Physiotherapy 81(6), 338-344.

Hannan, M.J.,\& Freeman, J.H. 1977. The Population Ecology of Organisations. American Journal of Sociology (82), 929-964.

Hannan, M.J.,\& Freeman, J.H. 1989 Organisational Ecology. Cambridge MA Harvard University Press.
Kuhn, T.S. 1970. The Structure of Scientific Revolutions. University of Chicago Press.

Michaels, M. 1976. WCPT Address Eighth International Congress. South African Journal of Physiotherapy 32(2), 16.

Mintzberg, H. 1979. The Structuring of Organisations. Prentice-Hall, Englewood-Cliffs.

Oliver, C. 1990. Determinants of Interorganisational Relationships. Academy Management Review 15(2), 241-265.

Paatero, H. 1982. Physiotherapy in Perspective. Congress proceedings, WCPT Ninth International Congress, 868-876.

Richardson, B. 1993. Practice, Research and Education - What is the link? Physiotherapy 79(5), 317-322.

Richardson,B. 1999. Professional Development. Physiotherapy, 85(9), 467-473

Tynne-Lenne, R.A. 1991. Towards a Physiotherapy Paradigm. In: Congress proceedings, Eleventh WCPT International Congress, 238-240.

Weber,M. 1947. The Theory of Social and Economic Organisations (Translated), Oxford University Press, New York.

\section{New Millennium Time to think of a change?}

Quality Locums are looking for quality personnel in all grades and specialities for work in the UK. Eligibility for a visa or work permit would be an advantage, but even if you are not eligible we would still like to hear from you as we may be able to

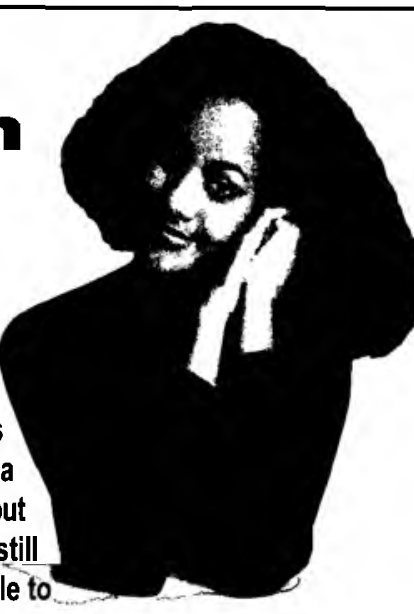
help. Quality Locums are the largest independent Medical, Care and Education Agency in the UK and we have branches in South Africa and Australia. We need Medical Staff of all specialities, Social Workers and Teachers urgently to fill full and part time positions throughout Great Britain and Ireland. We are experts at helping you to take advantage of the opportunities in the UK. Why not call one of our managers today for an informal discussion.

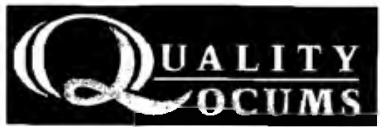

Sonja Lewis Quality Locums Cape Town Tel: 0214625357

Fax: 0214625390

Email: QualityLocums@Worldonline.co.za

Matt Wagner Quality Locums Durban Tel: 0314692098

Email Wagner@yebo.co.za

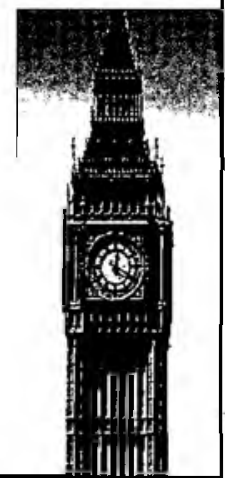

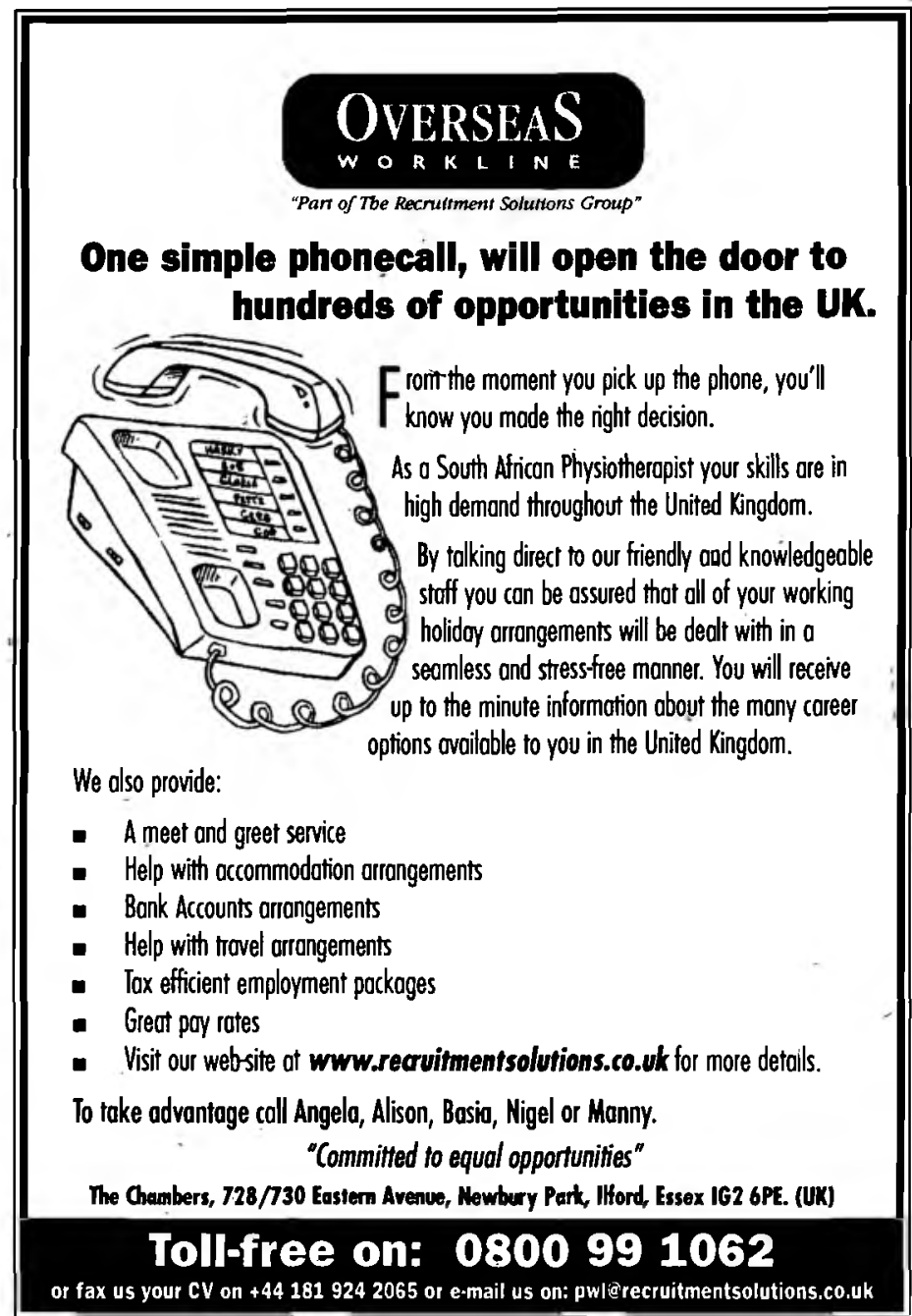

